\title{
Microbiological Characterization of Pure Geraniol and Comparison with Bactericidal Activity of the Cinnamic Acid in Gram-Positive and Gram- Negative Bacteria
}

\author{
Zanetti $\mathbf{M}^{1,2^{\star}}$, Ternus $Z^{2,5}$, Dalcanton $F^{4}$, de Mello MMJ $^{3,4}$, de Oliveira $D^{1}$, Araujo PHH ${ }^{1}$, Riella HG ${ }^{1}$ and Fiori MA ${ }^{3,4}$ \\ ${ }^{1}$ Post-Graduate Program in Chemical and Food Engineering, Universidade Federal de Santa Catarina, Florianópolis, Brazil \\ ${ }^{2}$ Area of exact and environmental sciences, Universidade Comunitária da Região de Chapecó, Brazil \\ ${ }^{3}$ Post-Graduate Program in Environmental Science, Universidade Comunitária da Região de Chapecó, Brazil \\ ${ }^{4}$ Post-Graduate Program in Technology and Management of the Innovation, Universidade Comunitária da Região de Chapecó, Brazil \\ ${ }^{5}$ Post-Graduate Program in Agricultural Microbiology and the Environment, Universidade Federal do Rio Grande do Sul, Porto Alegre, Brazil
}

\begin{abstract}
Geraniol is a terpene alcohol and the principal constituent compound of many essential oils of the aromatic plants. This molecule is very important for the flavors and fragrance industries due to its pleasant odor. The geraniol has the insecticidal properties and is an efficiently repellent agent and its toxicity is low. So, its antimicrobial ability can be explored to obtaining important additives for especial products applied in the food industry. The cinnamic acid is a molecule present in cinnamon oils and in coca leaves. This molecule also exhibits low toxicity and has a broad biological application spectrum for many microorganisms. This work evaluated the antimicrobial activity of the essential oil of geraniol and of the cinnamic acid against different microorganisms and compared their bactericidal activity for future applications as an additive for food packages. The bacteria studied were: Staphylococcus aureus, Listeria monocytogenes, Escherichia coli and Salmonella enterica. The Minimum Inhibitory Concentration test (MIC) and the Agar Diffusion Method were applied to available the antimicrobial susceptibility. The geraniol showed a large bactericidal activity and greater than the cinnamic acid for the bacteria studied. The geraniol showed the better bactericidal action and high application potential for use as an additive for treatment of the food or to produce active food packaging.
\end{abstract}

Keywords: Geraniol; Cinnamic acid; Antimicrobial compounds; Bactericidal compounds

\section{Introduction}

In recent years, aromatic plants and their extracts have been examined for their effectiveness for food safety and preservation applications [1-3] and have received attention as growth and health promoters [4]. Most of their properties are due to their essential oils (EOs) and other secondary plant metabolite components [4]. Biological activities of EOs include, but are not limited to, antibacterial, antifungal, antiviral, insecticidal, antioxidant and anticancer properties $[5,6]$. Essential oils have been documented to be effective antimicrobials against several foodborne pathogens including Escherichia coli O157:H7, Salmonella typhimurium, Staphylococcus aureus, Listeria monocytogenes, Campylobacter and others [7]. The use of natural essential oils as antimicrobial agents in food products may be considered as an additional key to increasing the security and shelf life [8].

Many authors have performed studies in vitro on antibacterial properties on several EOs $[9,10]$ finding minimal inhibitory concentrations (MIC) values very low $(<0,1 \%)$ against an initial

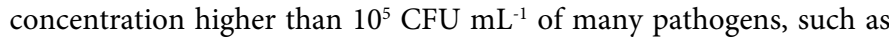
Staphylococcus aureus, Listeria monocytogenes, Salmonella enteritidis, Campylobacter jejuni and Escherichia coli [11].

Geraniol (3,7-dimethyl-octa-trans-2,6-dien-1-ol) is an acyclic monoterpene alcohol with the chemical formula $\mathrm{C}_{10} \mathrm{H}_{18} \mathrm{O}$ (Figure 1). The product referred to as "geraniol" is a mixture of the two cis-trans isomers properly named geraniol (Trans) and nerol (cis). Geraniol is a commercially important terpene alcohol occurring in the essential oils of several aromatic plants [12].

$\mathrm{Si}$ et al. evaluated the antimicrobial activity of sixty six types of essential oils and the geraniol showed antimicrobial effect for the bacteria Escherichia coli and Salmonella typhimurium greater than $80 \%$ for $500 \mu \mathrm{g} / \mathrm{ml}$ oil concentrations [13]. These works obtained antimicrobial activity results of the palmarosa oil ( $80 \%$ of geraniol in its composition) considered strong, and this oil showed MIC between 0.4 and $0.6 \mathrm{mg} \mathrm{L}^{-1}$ for Staphylococcus aureus and Escherichia coli [14]. The geraniol gas demonstrated the antimicrobial activity for the pathogens agent of the respiratory systems, including the bacteria Haemophilus influenzae, Streptococcus pneumoniae, Streptococcus pyogenes and Staphylococcus aureus [15].

The cinnamic acid, also known as 3-phenyl-2-propenoic acid (Figure 2) consists of a naturally occurring aromatic fatty acid originated from higher plants and found in Estoraques, cinnamon oils and coca leaves [16], has low toxicity and a broad spectrum of biological activities against numerous microorganisms [17]. Cinnamic acid derivatives typically have a broad spectrum of biological activity including antioxidant, cerebro-protective, hepato-protective, cholegogic, antiinflammatory, cytostatic, anti-hypoxic, hypolipidemic, anti-coagulant, anti-allergic, antimicrobial, etc. [18] and are widely used in food

*Corresponding author: Micheli Zanetti, Post-Graduate Program in Chemical and Food Engineering, Universidade Federal de Santa Catarina, Florianópolis, Brazil, Tel: 5548 3721-9000; E-mail: eng.miche@unochapeco.edu.br

Received May 31, 2015; Accepted June 18, 2015; Published June 25, 2015

Citation: Zanetti M, Ternus ZR, Dalcanton F, de Mello MM, de Oliveira D, et al (2015) Microbiological Characterization of Pure Geraniol and Comparison with Bactericidal Activity of the Cinnamic Acid in Gram-Positive and Gram- Negative Bacteria. J Microb Biochem Technol 7:4 186-193. doi:10.4172/1948-5948.1000203

Copyright: @ 2015 Zanetti M, et al. This is an open-access article distributed under the terms of the Creative Commons Attribution License, which permits unrestricted use, distribution, and reproduction in any medium, provided the original author and source are credited. 
Citation: Zanetti M, Ternus ZR, Dalcanton F, de Mello MMJ, de Oliveira D, et al. (2015) Microbiological Characterization of Pure Geraniol and Comparison with Bactericidal Activity of the Cinnamic Acid in Gram-Positive and Gram- Negative Bacteria. J Microb Biochem Technol 7:4 186-193. doi:10.4172/1948-5948.1000203

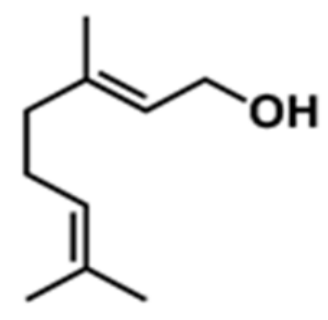

Figure 1: Chemical structure of the geraniol.

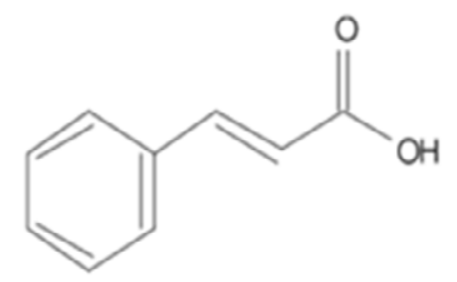

Figure 2: Chemical structure of the cinnamic acid.

additives [19]. Cinnamic acid is the main constituent of clove oil composing approximately (70 to $80 \%)$ followed by the composition of eugenol (4 to $7 \%)[20]$.

Many cinnamic acid derivatives, especially those with the phenolic hydroxyl group, are well-known antioxidants and are supposed to have several health benefits due to their strong free radical scavenging properties. It is also well known that cinnamic acid has antimicrobial activity. Cinnamic acid derivatives, both isolated from plant material and synthesized, have been reported to have anti-bacterial, anti-viral and anti-fungal properties [21].

Tests with cinnamic acid showed antibacterial activity against all the tested bacteria (Gram-positive bacteria Staphylococcus aureus (ATCC 6538), Bacillus cereus (clinical isolate), Listeria monocytogenes (NCTC 7973), Micrococcus flavus (ATCC 10240), Gram-negative bacterium Pseudomonas aeruginosa (ATCC 27853), Escherichia coli (ATCC 35210), Salmonella typhimurium (ATCC 13311) and Enterobacter cloacae (human isolate) with MIC $700-15000 \mu \mathrm{g} / \mathrm{ml}$ [22].

Many studies mention the antimicrobial activity of Cymbopogon martinii, commonly known the palmarosa or rosa grass, that is a perennial aromatic grass, known for its rose like aroma essential oil and refer this activity to geraniol. The essential oil obtained from genuine Cymbopogon martinii is commonly known in trade palmarosa oil, which contains geraniol and geranyl acetate the major compounds [23]. Whole plant contains essential oil of palmarosa, but maximum amount of oil and geraniol are reported in flowering tops [24]. The characteristic odor of palmarosa oil is attributed to the high content of geraniol and varying amounts of geranyl acetate [25].

Several authors refer to antimicrobial activity palmarosa to geraniol in that it is in higher concentration, but it is known that palmarosa extract is composed of various other oils and esters, including the geranyl acetate, which is also widely quoted in the literature as possessing antimicrobial activity $[26,23,27]$. Therefore, the need for further work, which can demonstrate antimicrobial activity of geraniol pure oil.

The aim of this study was to evaluate the minimum inhibitory concentration and the antimicrobial sensitivity of the essential oil of geraniol and cinnamic acid against different microorganisms Staphylococcus aureus, Listeria monocytogenes, Escherichia coli and Salmonella enterica.

\section{Material and Methods}

\section{Microorganisms and inoculum preparation}

The geraniol and cinnamic acid were obtained as analytical standards from Sigma Aldrich. Antibacterial activity tests were performed with standard Gram-positive strains, Staphylococcus aureus (ATCC 25923) (Bioscan) and Listeria monocytogenes (ATCC 19111) (Bioscan), Gram-negative strains, Escherichia coli (ATCC 25922) (Bioscan) and Salmonella enterica (ATCC 14028) (Bioscan).

Using a sterile loop seeding the microorganisms were transferred to cultures on nutrient agar - AN (Kasvi) for brain-heart broth tubes - BHI (Kasvi) and incubated in a greenhouse bacteriological (Quimis, modelo Q316M4) with controlled temperature of $35 \pm 1^{\circ} \mathrm{C}$ for $24 \mathrm{~h}$. After the incubation process the bacterial suspensions were adjusted in sterile $0.9 \%$ saline (synth), in order to obtain an optical turbidity comparable to McFarland 0.5 standard solution with an approximate

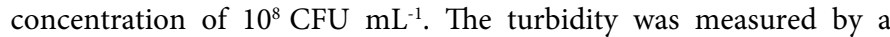
spectrophotometer (Biospectro, Model SP22) and transmittance signals at wavelength of $625 \mathrm{~nm}$. Likewise, the bacterial suspension was diluted and adjusted to an approximate concentration of $10^{4} \mathrm{CFU} \mathrm{mL} \mathrm{mL}^{-1}$.

\section{Diffusion assay of agar}

The antimicrobial activity of the geraniol and cinnamic acid was assessed using a diffusion test results with pit on solid medium (agar), following the method of susceptibility testing for antimicrobial agents described by the standard CLSI with modifications.

With the aid of sterile cotton swab, the bacterial suspensions of the different micro-organisms $\left(10^{4} \mathrm{CFU} \mathrm{ml}{ }^{-1}\right)$ were inoculated on the surfaces of Plate Count Agar - PCA (Kasvi). After 5 minutes, were made holes (wells) $5 \mathrm{~mm}$ in diameter and PCA with the aid of a micropipette (Brand) were filled with geraniol or cinnamic acid. The plates were incubated in bacteriological oven (Quimis, model Q316M4) controlled temperature of $35 \pm 1^{\circ} \mathrm{C}$. After $18 \mathrm{~h}$ the diameters of inhibition zones were measured using a millimeter ruler. All agar diffusion tests were performed in triplicate for each organism.

\section{Determination of minimum inhibitory concentration (MIC)}

The determination of the minimum inhibitory concentration (MIC) was performed according to the procedures described by [28] with some modifications. The geraniol and cinnamic acid were initially diluted to a concentration of $10000 \mu \mathrm{g} \mathrm{mL}^{-1}$ in an aqueous solution containing $10 \%$ of volume of dimethyl sulfoxide (DMSO - Vetec). The micro dilution test was performed in sterile 96-well microplates shaped bottom "U" containing $100 \mu \mathrm{L}$ of BHI (brain-heart infusion broth). Then $200 \mu \mathrm{L}$ of the diluted solutions geraniol and cinnamic acid was added to the wells. The tests were performed in triplicate and denominated by $\mathrm{A} 1, \mathrm{~A} 2$ and $\mathrm{A} 3$ for the samples containing cinnamic acid and A5, A6 and A7 for the samples containing geraniol. After homogenization of the sample (line A) $100 \mu \mathrm{L}$ aliquots of each solution were successively transferred to new microplates, to obtain solutions with different concentrations, Table 1.

In the solutions shown in Table 1 , were added $5 \mu \mathrm{L}$ of bacterial inoculum of Staphylococcus aureus, Listeria monocytogenes, Escherichia coli and Salmonella enterica, prepared with concentration of $10^{4} \mathrm{CFU}$ 
Citation: Zanetti M, Ternus ZR, Dalcanton F, de Mello MMJ, de Oliveira D, et al. (2015) Microbiological Characterization of Pure Geraniol and Comparison with Bactericidal Activity of the Cinnamic Acid in Gram-Positive and Gram- Negative Bacteria. J Microb Biochem Technol 7:4 186-193. doi:10.4172/1948-5948.1000203

$\mathrm{mL}^{-1}$. The different solutions were coded as sample number 10,11 and 12 and used as control solutions for experimental testing. The code solutions number 10 were used as the negative control in the inhibitory activity of the DMSO solvent used in the preparation of all the bacterial solutions. Solutions containing 10\% DMSO were diluted in Mueller-Hinton broth as the equivalent concentration of $78.125 \mathrm{mg}$ $\mathrm{L}^{-1}$ (equivalent to $\mathrm{H}$ sample) and the same inoculum was added. The solutions coded as 11 samples were prepared containing BHI broth and only the inoculum in order to serve as the positive control of bacterial

\begin{tabular}{|c|c|}
\hline Sample & Concentration of Geraniol or Cinnamic Acid $\left(\boldsymbol{\mu g} \mathbf{~ m L}^{-1}\right)$ \\
\hline A & 10000 \\
\hline B & 5000 \\
\hline C & 2500 \\
\hline D & 1250 \\
\hline E & 625 \\
\hline F & 312.5 \\
\hline G & 156.25 \\
\hline H & 78.125 \\
\hline
\end{tabular}

Table 1: Solutions with different concentrations of geraniol or cinnamic acid.

\section{$3 a$}

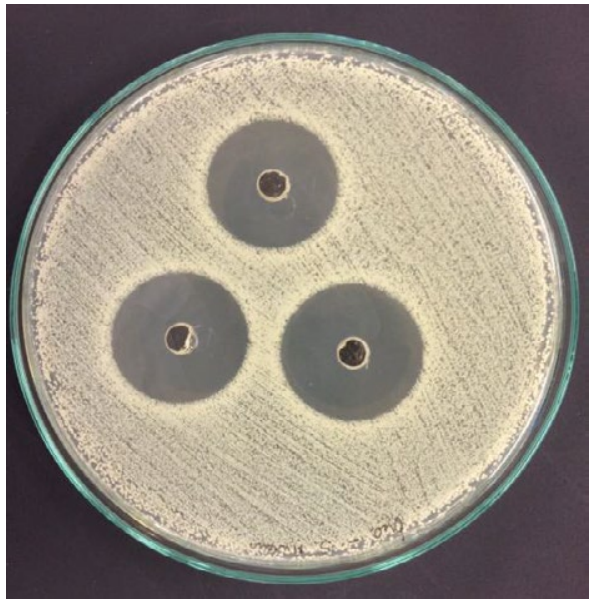

$3 c$

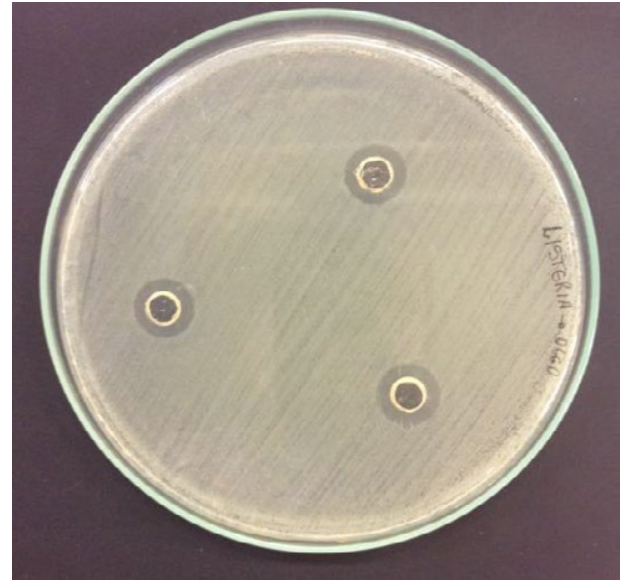

Figure 3: Diffusion test results in agar for the geraniol with different bacteria. (a) Staphylococcus aureus, (b) Escherichia coli, (c) Listeria monocytogenes and (d) Salmonella enterica

viability. A solution was prepared containing only Mueller-Hinton broth with the aim of verifying the sterility of the plate.

The microplates were incubated in a microbiological incubator with controlled temperature $35^{\circ} \mathrm{C}$ for $20 \mathrm{~h}$. After the incubation was added to each microplate $20 \mu \mathrm{L}$ of an aqueous solution of $0.5 \%$ TTC (triphenyl tetrazolium chloride -Sigma-Aldrich) and the microplates were re-incubated for another $4 \mathrm{~h}$. After the last incubation, the presence of the red coloration in the holes indicated microbial growth, while the absence of color indicated the inhibitory activity of the samples geraniol and cinnamic acid.

\section{Results and Discussion}

\section{Microbiological tests}

Figure 3 shows the results of agar diffusion test for the pure geraniol oil with different types of bacteria and the Table 2 shows the average diameter of the halo inhibition measured for agar diffusion tests. The geraniol showed an excellent antimicrobial activity for the four bacteria tested and a bactericidal effect. In the agar diffusion test for bacteria type Staphylococcus aureus the halo average diameter of the
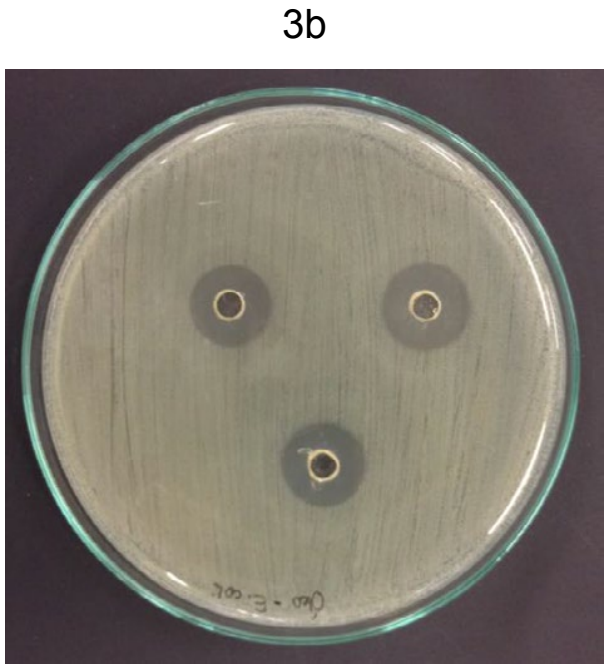

$3 d$

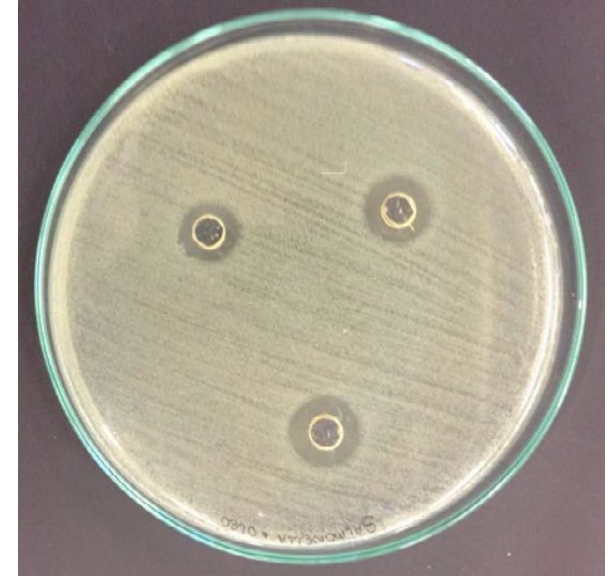


Citation: Zanetti M, Ternus ZR, Dalcanton F, de Mello MMJ, de Oliveira D, et al. (2015) Microbiological Characterization of Pure Geraniol and Comparison with Bactericidal Activity of the Cinnamic Acid in Gram-Positive and Gram- Negative Bacteria. J Microb Biochem Technol 7:4 186-193. doi:10.4172/1948-5948.1000203

inhibition zone was $(35.3 \pm 0.08) \mathrm{mm}$. For the bacteria Escherichia coli, the halo average diameter was $(25.5 \pm 0.05) \mathrm{mm}$ and for the Salmonella enterica the halo average diameter was $(17.6 \pm 0.15) \mathrm{mm}$. For Listeria monocytogenes the average diameter was $(15.8 \pm 0.04) \mathrm{mm}$.

According to the antimicrobial activity rating from agar diffusion tests established by Ponce et al. the geraniol is a compound microbiologically very active for the bacteria Staphylococcus aureus, Escherichia coli, Salmonella enterica and microbiologically active for the bacterium Listeria monocytogenes [29]. The method establishes that average diameters of halos of inhibition smaller than $9 \mathrm{~mm}$ should be considered microbiologically not active; average diameters between 9

\begin{tabular}{|l|l|l|l|l|}
\hline \multirow{2}{*}{ Samples } & \multicolumn{4}{|c|}{ Mean ( \pm SD) diameter values for the inhibition halos (mm) } \\
\cline { 2 - 5 } & \multicolumn{4}{|c|}{ Microorganisms } \\
\cline { 2 - 5 } & S.aureus & E.coli & L.monocytogenes & S.enterica \\
\hline Geraniol & $35.3 \pm 0.08$ & $25.5 \pm 0.05$ & $15.8 \pm 0.04$ & $17.6 \pm 0.15$ \\
\hline Cinnamic acid & $16.5 \pm 0.10$ & $11.0 \pm 0.06$ & $14.7 \pm 0.12$ & $14.8 \pm 0.04$ \\
\hline
\end{tabular}

Table 2: Average diameter values for the inhibition halos in agar diffusion test for the geraniol and cinnamic acid using different types of bacteria: Staphylococcus aureus, Escherichia coli, Listeria monocytogenes and Salmonella enterica. and $14 \mathrm{~mm}$ microbiologically active part; average diameters between 14 and $17 \mathrm{~mm}$ microbiologically active and higher average diameters $17 \mathrm{~mm}$ microbiologically very active.

The cinnamic acid showed less antimicrobial activity than geraniol. The Figure 4 shows the results of microbiological tests by agar diffusion obtained for pure cinnamic acid and different types of bacteria. For bacteria of type Staphylococcus aureus the average diameter of the inhibition halo was $(16.5 \pm 0.10) \mathrm{mm}$ and for the bacteria of the type Salmonella enterica $(14.8 \pm 0.04) \mathrm{mm}$. For bacteria type Listeria monocytogenes the average diameter of the inhibition halo was (14.7 $\pm 0.12) \mathrm{mm}$ and for the bacteria type Escherichia coli halo average diameter was $(11.0 \pm 0.06) \mathrm{mm}$. Following the classification of Ponce [29], cinnamic acid is a microbiologically active compound for the bacteria Staphylococcus aureus, Salmonella enterica, and Listeria monocytogenes. For bacteria type Escherichia coli cinnamic acid is microbiologically active part.

In addition, essential oils are known to exhibit antimicrobial activity against a wide range of bacteria and fungi. The antimicrobial activity of essential oils is due to their solubility in the phospholipid bilayer of cell membranes [30]. It was also reported that the antibacterial activities
$4 a$

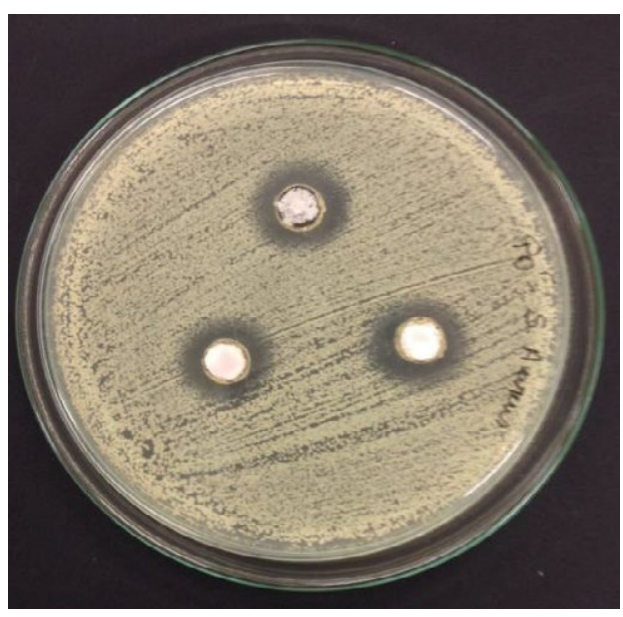

$4 c$

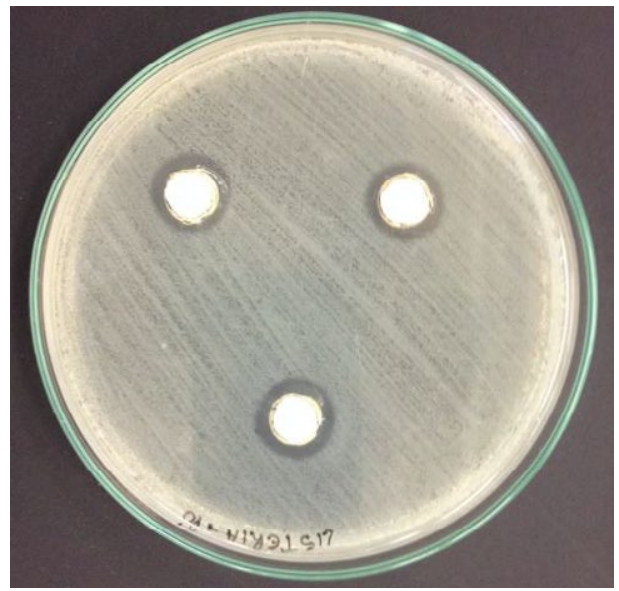

$4 b$

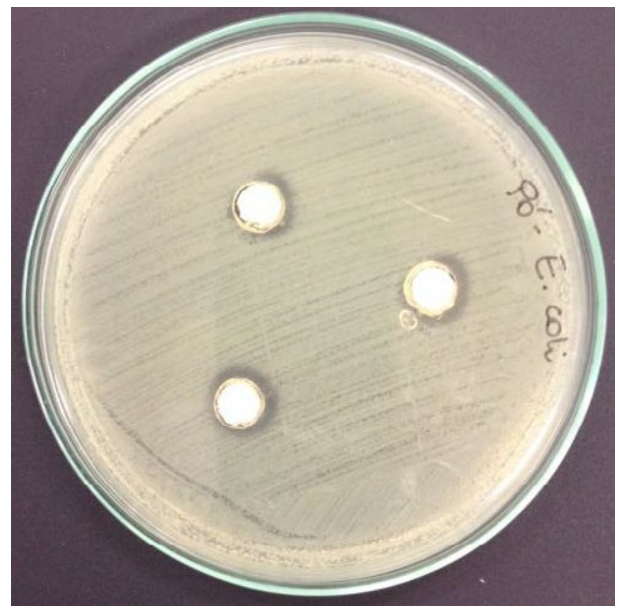

$4 d$

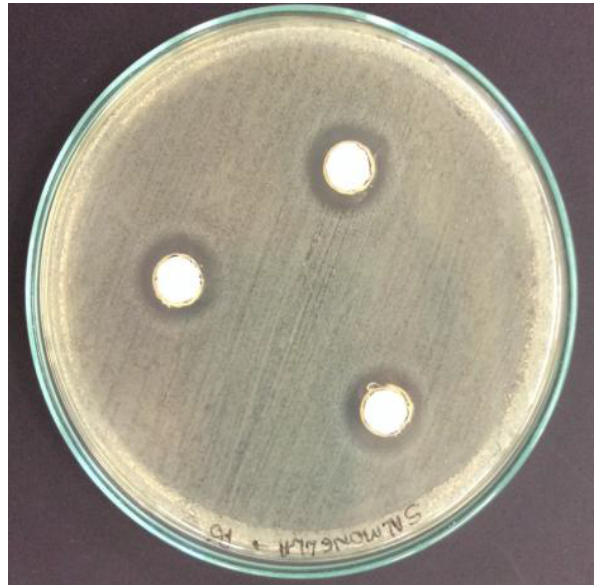

Figure 4: Diffusion test results in agar for the cinnamic acid with different bacteria. (a) Staphylococcus aureus, (b) Escherichia coli, (c) Listeria monocytogenes and (d) Salmonella enterica 
of monoterpene alcohols (including linalool, nerol, citronellol and geraniol) are more effective than their antifungal activity [31]. Assays have shown that geraniol demonstrates good activity in modulating drug resistance of several Gram-negative bacterial species (E. aerogenes, E. coli, $P$. aeruginosa) by targeting efflux mechanisms and could restore drug susceptibility in strains that overexpress efflux pumps [32].

The results of the microbiological agar diffusion tests show that geraniol has antimicrobial activity against all types of bacteria studied. The cinnamic acid, despite having less antimicrobial activity also inhibits bacterial growth of the studied strains.

The greatest antimicrobial activity geraniol oil is probably due to its greater hydrophobicity. Some authors have shown that natural extracts have high hydrophobicity and therefore cross bacterial membranes with high easily, leading to loss of ions and reducing the electric potential of membranes and loss of function of protons and decreased ATP. These changes promote cell death of the bacteria [33].

Table 3 shows the results of the minimum inhibitory concentration test (MIC) for the four bacteria studied, the compounds held geraniol and cinnamic acid. The minimum concentration of geraniol required for the inhibition of growth was lower for Escherichia coli and Listeria monocytogenes, being $2500 \mu \mathrm{g} \mathrm{mL}^{-1}$. For Staphylococcus aureus and Salmonella enterica concentration was $5000 \mu \mathrm{g} \mathrm{mL}^{-1}$. Cinnamic acid a concentration of $10000 \mu \mathrm{g} \mathrm{mL} \mathrm{m}^{-1}$ was required to inhibit the growth of bacteria assessed, being a concentration at least twice that of geraniol. The minimum inhibitory concentration was not associated with the type of cell wall of bacteria, Gram-positive or Gram-negative.

Figure 5 compares the microbiological results obtained for the geraniol and cinnamic acid and shown that geraniol has greater antimicrobial activity than cinnamic acid. For the four types of bacteria evaluated geraniol showed greater antimicrobial activity of cinnamic acid in the agar diffusion test, Figure 5a, and the inhibition tests, Figure 5b.

\section{Application options as antimicrobial}

The tested bacteria have causing various diseases to humans and animals. The bacterium Staphylococcus aureus cause foodborne diseases and infections ranging from minor skin disorders localized to the deep tissue and life-threatening systemic disease. The bacteria Escherichia coli are facultative anaerobic and are associated with urinary tract infections and nosocomial infections in humans [32].

Salmonella enterica is associated with different clinical manifestations: gastroenteritis, bacteremia, enteric fever, and an asymptomatic carrier state and is more common in children under the age of 5, adults 20-30 year olds, and patients 70 years or older [34-36].

Listeria monocytogenes is a facultative anaerobic Gram-positive bacteria and capable of causing diseases in humans. According to the European Authority for Food Safety (EFSA), L. monocytogenes is considered a microorganism of concern because, although their incidence in the population is relatively low, remains in the body for a long time, causing the hospitalization people had $99.1 \%$ of the confirmed cases, with a mortality rate of $15.6 \%$ in 2013 [37-39]. In the

\begin{tabular}{|c|c|c|c|c|}
\hline \multirow{2}{*}{ Compound } & \multicolumn{4}{|c|}{ MIC ( $\left.\boldsymbol{\mu g ~ m L}^{-1}\right)$} \\
\cline { 2 - 5 } & S.aureus & E.coli & L.monocytogenes & S.enterica \\
\hline Geraniol & 5000 & 2500 & 2500 & 5000 \\
\hline Cinnamic acid & 10000 & 10000 & 10000 & 10000 \\
\hline
\end{tabular}

Table 3: Results of the minimum inhibitory concentration test (MIC) for the geranio and cinnamic acid using different bacteria: Staphylococcus aureus, Escherichia coli, Listeria monocytogenes and Salmonella enterica.
US, were reported 103 cases of human listeriosis, of which 15 resulted in death, in 2011, all associated with L. monocytogenes [40]. Consequently, in recent decades, researchers have devoted intense efforts to decrease the incidence of this pathogen mainly in food and the use of geraniol and cinnamic acid may be an excellent alternative.

The results of this work show that the pure geraniol oil has great antimicrobial activity to the broad spectrum of pathogenic bacteria evaluated. Compared with cinnamic acid geraniol oil inhibits the growth and has higher antimicrobial activity for both Gram-negative and Gram-positive for bacteria.

These characteristics add various application possibilities for the oil geraniol. Its high antimicrobial activity and associated with the inhibition capacity of a large number of bacteria can be exploited for the development of antimicrobial technologies for food protection, control and prevention of infections in environments frequented by human beings or animals, or for the synthesis of new compounds with antimicrobial properties, as is the case of geraniol esters.

Nowadays, the approaches that can be adopted in food preservation include: (a) aseptic handling and packaging, (b) the mechanical removal of microorganisms by washing or filtration, (c) destruction of microorganisms by physical or chemical sanitization and finally (d) the inhibition of pathogens or saprophytes through environmental control [41]. Recent developments in nanotechnology have brought significant advances in the development of active packaging using antimicrobial compounds in its composition.

Inhibition of microbial growth through environmental control is achieved through the addition of chemical compounds (antimicrobial preservatives) with an inhibitory or bactericidal/fungicide activity [42]. In the last years, natural antimicrobials have attracted considerable attention due to the increased consumer awareness on the aspects of food quality and safety $[41,43,44]$.

Nano encapsulation of bioactive compounds represents a viable and efficient approach to increasing the physical stability of the active substances, protecting them from the interactions with the food ingredients and, because of the subcellular size, increasing their bioactivity [42]. Several encapsulation systems, with different formulations and size distributions were tested for the delivery of essential oils in foods. For example, the use of a solid-fat micrometric emulsion was reported to reduce the volatility of the antimicrobial agent, entrapped into the crystallized-fat structure, thus protecting the active compounds against environmental factors [45].

Some authors evaluated several EOs for antibacterial activity against the E. coli O157:H7 and Salmonella hadar in apple juice. Compounds most active against E. coli included carvacrol, oregano oil, geraniol, eugenol, cinnamon leaf oil, citral, clove bud oil, lemon grass oil, cinnamon bark oil, and lemon oil. The most active compounds against S. Hadar were Melissa oil, carvacrol, oregano oil, terpeineol, geraniol, lemon oil, citral, lemon grass oil, cinnamon leaf oil and linalool [46].

In addition to the acids most frequently added to melon and watermelon juices, essential oils have also been studied to improve the microbiological safety of these substrates [47]. Geraniol was added at concentration of $10 \mu \mathrm{g} / \mathrm{ml}$ to inactivate Salmonella enterica serovar typhimurium completely (>8 $\log 10$ cycles) in melon juices (pH 5.91) [48].

The geraniol and cinnamic acid present many interesting biological properties, in addition to antimicrobial properties, which can be applied to the development of methodologies and technologies for the protection and conservation of food. These compounds are non-toxic, 
Citation: Zanetti M, Ternus ZR, Dalcanton F, de Mello MMJ, de Oliveira D, et al. (2015) Microbiological Characterization of Pure Geraniol and Comparison with Bactericidal Activity of the Cinnamic Acid in Gram-Positive and Gram- Negative Bacteria. J Microb Biochem Technol 7:4 186-193. doi:10.4172/1948-5948.1000203

(a)

WIIt Geraniol
Cinamic Acid

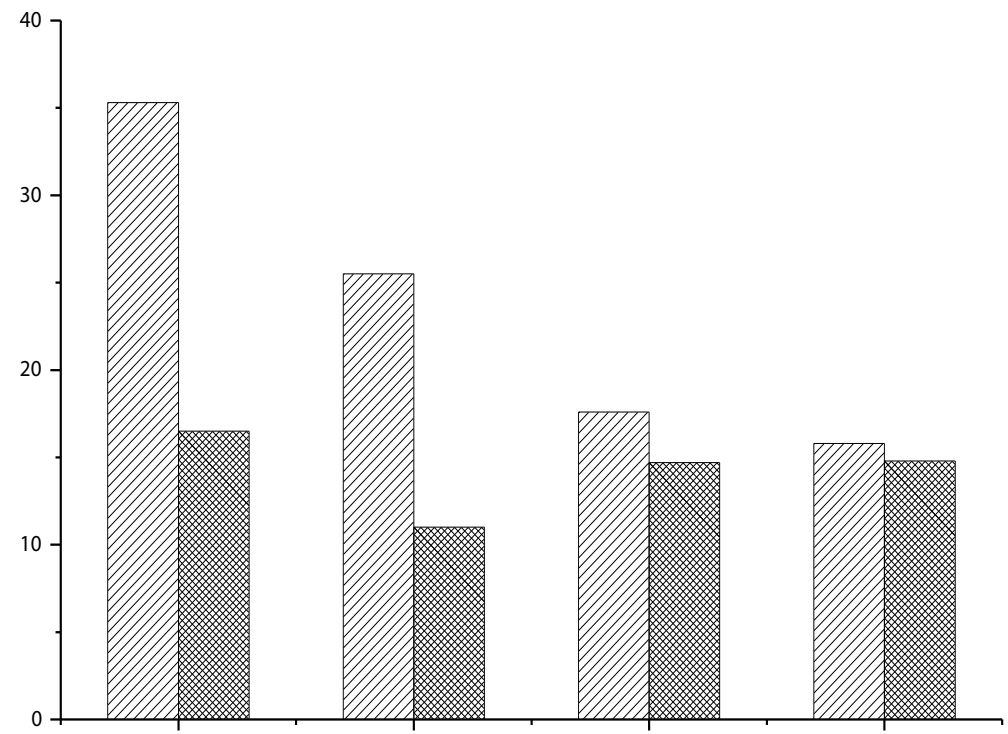

$s^{2 v^{2 e^{e^{5}}}}$

$\varepsilon^{0 "}$
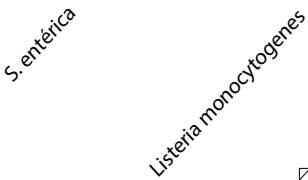

(b)

VIIIA Geraniol
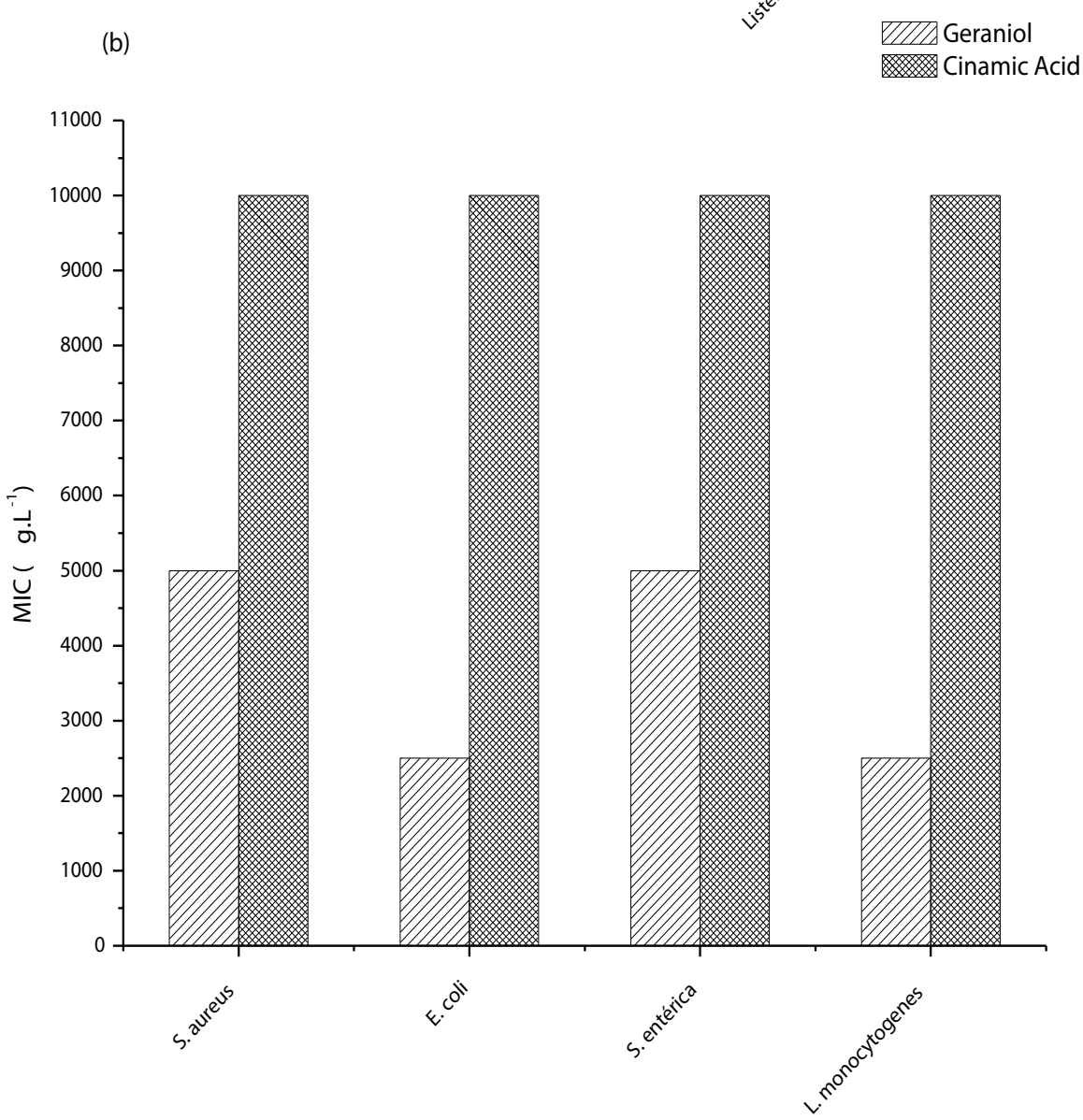

Figure 5: Comparison of the microbiological results obtained for the geraniol and cinnamic acid with the bacteria Staphylococcus aureus, Escherichia coli, Listeria monocytogenes and Salmonella enterica. (a) Difusion test and (b) Minimum inhibitory concentration test (MIC). 
Citation: Zanetti M, Ternus ZR, Dalcanton F, de Mello MMJ, de Oliveira D, et al. (2015) Microbiological Characterization of Pure Geraniol and Comparison with Bactericidal Activity of the Cinnamic Acid in Gram-Positive and Gram- Negative Bacteria. J Microb Biochem Technol 7:4 186-193. doi:10.4172/1948-5948.1000203

have antioxidant and anti-inflammatory activity. These properties associated with high antimicrobial activity demonstrated by this study show the high application potential of these compounds and instigate new and further study of its application. Motivate studies to explore the consumer product formulation containing viability geraniol, cinnamic acid or its derivatives. Likewise, motivate future studies to evaluate the technical feasibility of the application of production of antimicrobial additives, non-toxic, antioxidants and anti-inflammatory drugs with potential application in cosmetics, active packaging for foods, biological membranes and using physician.

Recent studies cite the high antimicrobial activity against various microorganisms of the nerol compound, which is the cis-isomer of geraniol [49-51]. Some authors mention that the geraniol and the nerol have double bonds in their molecules, so, these showed greater antimicrobial activity against the bacteria tested, in comparison with other essential oils tested that have single bond [52]. The details about these microbiological properties not are shown by the scientific literature. More results indicating the relationship of the structure, specifically the relationship of the microbiological properties with the position of the $\mathrm{OH}$ group in the structure of the geraniol and nerol, are excellent opportunities for new scientific studies in future works.

\section{Conclusions}

The compounds tested geraniol and cinnamic acid, exhibit activity against pathogens studied, Staphylococcus aureus, Listeria monocytogenes, Escherichia coli and Salmonella enterica, being geraniol a compound that deserves attention for being very active for three of the four bacteria tested. Future research may focus on the efficacy of these compounds in various industrial applications. The synergism of these compound and processing techniques have to be investigated for potential commercial applications as a new additive for foods and packaging foods.

\section{References}

1. Fisher K, Phillips CA (2008) Potential antimicrobial uses of essential oils in food: is citrus the answer? Trends in Food Science and Technology 19: 156-164.

2. Gyawali R, Ibrahim S A (2014) Natural products as antimicrobial agents. Food Control 46: 412-429.

3. Prakash B, Media A, Mishra PK, Dubey NK (2015) Plant essential oils as food preservatives to control moulds, mycotoxin contamination and oxidative deterioration of agri-food commodities e potentials and challenges. Food Control 47: 381-391.

4. Brenes A, Roura E (2010) Essential oils in poultry nutrition: main effects and modes of action. Animal Feed Science and Technology 158: 1-14.

5. Burt S (2004) Essential oils: their antibacterial properties and potential applications in foods--a review. Int J Food Microbiol 94: 223-253.

6. Kordali S, Kotan R, Mavi A, Cakir A, Ala A, et al. (2005) Determination ofthe chemical composition and antioxidant activity of the essential oil of Artemisia dracunculus and of the antifungal and antibacterial activities of Turkish Artemisia absinthium, A. dracunculus, Artemisia santonicum, and Artemisia spicigera essential oils. J Agric Food Chem 53: 9452-9458.

7. Callaway TR, Carroll JA, Arthington JD, Edrington TS, Anderson RC, et al (2011) Citrus products and their use against bacteria: potential health and cost. Humana Press, New York.

8. Aquino LCL, Santos G G, Trindade R C, Alves J A B, Santos P O (2010) Antimicrobial activity of essential oils of cidreira-herb and basil against bacteria from bovine meat. Alim. Nutr 21: 529-535.

9. Bakkali F, Averbeck S, Averbeck D, Idaomar M (2008) Biological effects of essential oils--a review. Food Chem Toxicol 46: 446-475.

10. Hyldgaard M, Mygind T, Meyer RL (2012) Essential oils in food preservation: mode of action, synergies, and interactions with food matrix components. Front Microbiol 3: 12
11. Pesavento G, Calonico C, Bilia AR, Barnabei M, Calesini F et al. (2015) Antibacterial activity of Oregano, Rosmarinus and Thymus essential oils against Staphylococcus aureus and Listeria monocytogenes in beef meatballs. Food Control 54: 188-199.

12. Chen W, Viljo AM (2010) Geraniol-a review of a commercially important fragrance material. Safr J Bot 76: 643-651.

13. Si W, Gong J, Tsao R, Zhou T, Yu H, et al. (2005) Antimicrobial activity of essential oils and structurally related synthetic food additives towards selected pathogenic and beneficial gut bacteria. Journal of Applied Mibrobiology 100 296-305.

14. Scherer R, Wagner R, Duarte MCT, Godoy HT (2009) Composição e atividades antioxidante e antimicrobiana dos óleos essenciais de cravo-da-índia, citronela, e palmarosa. Ver. Bras. PI. Med. Botucatu 11: 442-449.

15. Inouye S, Takizawa T, Yamaguchi H (2001) Antibacterial activity of essentia oils and their major constituents against respiratory tract pathogens by gaseous contact. J Antimicrob Chemother 47: 565-573.

16. Liu L, Hudgins WR, Shack S, Yin MQ, Samid D (1995) Cinnamic acid: a natural product with potential use in cancer intervention. Int J Cancer 62: 345-350.

17. Dorman HJ, Deans SG (2000) Antimicrobial agents from plants: antibacterial activity of plant volatile oils. J Appl Microbiol 88: 308-316

18. Avanesyan AA, Pashkov AN, Simonyan NA, Simonyan AV, Myachina OV (2009) Antiradical activity of cinnamon acid derivates. Pharmaceutical Chemistry Journal 43: 18-19.

19. Adisakwattana S, Sompong W, Meeprom A, Ngamukote S, Yibchok-Anun $S$ (2012) Cinnamic acid and its derivatives inhibit fructose-mediated protein glycation. Int J Mol Sci 13: 1778-1789.

20. Matan N, Rimkeeree H, Mawson AJ, Chompreeda P, Haruthaithanasan V, et al. (2006) Antimicrobial activity of cinnamon and clove oils under modified atmosphere conditions. International Journal of Food Microbiology 107: 180-185.

21. Sova M (2012) Antioxidant and antimicrobial activities of cinnamic acid derivatives. Mini Rev Med Chem 12: 749-767.

22. Heleno SA, Ferreira ICFR, Esteves AP, Ciric' A, Glamoclija J, et al. (2013) Antimicrobial and demelanizing activity of Ganoderma lucidum extract, p-hydroxybenzoic and cinnamic acids and their synthetic acetylated glucuronide methyl esters. Food and Chemical Toxicology 58: 95-100.

23. Smitha GR, Virendra SR (2015) Variations in essential oil yield, geraniol and geranyl acetate contents in palmarosa (Cymbopogon martinii, Roxb. Wats. var motia) influenced by inflorescence development. Industrial Crops and Products 66: $150-160$

24. Agarwal KK (2008) Chemical Composition of Major Essential Oils of India. Swaraj Herbal Plants Ltd, Barabanki, Uttar Pradesh, India.

25. Husain A (1994) Essentials Oil Plants and their Cultivation. Central Institute of Medicinal and Aromatic Plants (CSIR), Lucknow, India.

26. Gonçalves MJ, Cruz MT, Tavares AC, Cavaleiroa C, Lopes MC, et al. (2012) Composition and biological activity of the essential oil from Thapsia minor, a new source of geranyl acetate. Industrial Crops and Products 35: 166-171.

27. Oussalah M, Caillet S, Saucier L, Lacroix M, (2007) Inhibitory effects of selected plant essential oils on the growth of four pathogenic bacteria: E. coli O157:H7, Salmonella typhimurium, Staphylococcus aureus and Listeria monocytogenes. Food Control 18: 414-420

28. Weerakkody NS, Caffin N, Turner MS, Dykes GA (2010) In vitro antimicrobial activity of less-utilized spice and herb extracts against selected foodborne bacteria. Food Control 2: 1408-1414.

29. Ponce AG, Fritz R, Del Valle CE, Roura SI (2003) Antimicrobial activity of essential oils on native microbial population of organic Swiss chard. Lebensmittel-Wissenschaft undTechnology 36: 679-684.

30. Knobloch K, Pauli A, Iberl B, Weigand H, Weis N (1989) Antibacterial and antifungal properties of essential oil components. Journal of Essential Oil Research 1: 119-128.

31. Suppakul P, Miltz J, Sonneveld K, Bigger SW (2003) Antimicrobial properties of basil and its possible application in food packaging. J Agric Food Chem 51 : 3197-3207.

32. Solórzano-Santos F, Miranda-Novales MG (2011) Essential oils from aromatic herbs as antimicrobial agents. Curr Opin Biotechnol 23: 1-6. 
Citation: Zanetti M, Ternus ZR, Dalcanton F, de Mello MMJ, de Oliveira D, et al. (2015) Microbiological Characterization of Pure Geraniol and Comparison with Bactericidal Activity of the Cinnamic Acid in Gram-Positive and Gram- Negative Bacteria. J Microb Biochem Technol 7:4 186-193. doi:10.4172/1948-5948.1000203

33. Di Pasqua R, Hoskins N, Betts G, Mauriello G (2006) Changes in membrane fatty acids composition of microbial cells induced by addiction of thymol, carvacrol, limonene, cinnamaldehyde, and eugenol in the growing media. Journal of Agricultural and Food Chemistry 54: 2745-2749.

34. Ryan KJ, Ray CG (2004) Sherris Medical Microbiology: An Introduction to Infectious Disease. (4thedn) McGraw-Hill, New York.

35. Giannella RA (1996) Salmonella. In: Baron's Medical Microbiology (4thedn) Univ of Texas Medical Branch.

36. Swanson SJ, Snider C, Braden CR, Boxrud D, Wünschmann A, et al. (2007) Multidrug-resistant Salmonella enterica serotype typhimurium associated with pet rodents. N Engl J Med 356: 21-28.

37. Eurosurveillance editorial team (2013) The European Union summary report on trends and sources of zoonoses, zoonotic agents and food-borne outbreaks in 2011 has been published. Euro Surveill 18: 20449

38. Ferreira V, Wiedmann M, Teixeira P, Stasiewicz MJ (2014) Listeria monocytogenes persistence in food-associated environments: epidemiology, strain characteristics and implications for public health. J Food Prot 77: 150-170.

39. Simoes M, Simoes LC, Vieira MJ (2010) A review of current and emergent biofilm control strategies. LWT Food Sci Technol 43: 573-583.

40. Centers for Disease Control and Prevention1 (2011) Multistate outbreak of listeriosis associated with Jensen Farms cantaloupe United States.

41. Davidson PM, Sofos JN, Branen AL (2005) Antimicrobials in food. Boca Raton FL: CRC Press.

42. Donsì F, Annunziata M, Sessa M, FerrariG (2011) Nanoencapsulation of essential oils to enhance their antimicrobial activity in foods. LWT - Food Science and Technology 44: 1908-1914.

43. Weiss J, Gaysinksy S, Davidson M, McClements J (2009) Nanostructured encapsulation systems: food antimicrobials. Global issues in food science and technology. Amsterdam: Elsevier Inc.
44. Gaysinsky S, Taylor TM, Davidson PM, Bruce BD, Weiss J (2007) Antimicrobia efficacy of eugenol microemulsions in milk against Listeria monocytogenes and Escherichia coli O157:H7. J Food Prot 70: 2631-2637.

45. Gavini E, Sanna V, Sharma R, Juliano C, Usai M, et al. (2005) Solid lipid microparticles (SLM) containing juniper oil as anti-acne topical carriers: preliminary studies. Pharmaceutical Development and Technology 10: 479-487.

46. Friedman M, Henika PR, Levin CE, Mandrell RE (2004) Antibacterial activities of plant essential oils and their components against Escherichia coli O157:H7 and Salmonella enterica in apple juice. Journal of Agriculture and Food Chemistry 52: 6042-6048.

47. Pina-Pérez MC, Rodrigo D, Martinez A (2015) Using natural antimicrobials to enhance the safety and quality of fruit- and vegetable-based beverages. Handbook of Natural Antimicrobials for Food Safety and Quality, Wood head publishing

48. Raybaudi-Massilia RM, Mosqueda-Melgar J, Martín-Belloso, O (2006) Antimicrobial activity of essential oils on Salmonella Enteritidis, Escherichia coli, and Listeria innocua in fruit Juices. Journal of Food Protection 69: 1579 -1586 .

49. Gyawali R, Ibrahim SA (2014) Natural products as antimicrobial agents. Food Control 46: 412-429.

50. Lang G, Buchbauer G (2008- 2010) A review on recent research results on essential oils as antimicrobials and antifungals. A review Flav Frag 27: 13-39.

51. Zineb J, Yassine EA, Badiaa L, Abdelfattah A (2015) Phytochemistry of the essential oil of Melissa officinalis L. growing wild in Morocco: Preventive approach against nosocomial infections. Asian Pac J Trop Biomed 5: 458-461.

52. Gochev V, Dobreva A, Girova T, Stoyanova A (2010) Antimicrobial activity of essential oil from Rosa alba. Biotechnology and Biotechnological Equipment 24: $512-515$ 